IJUSEng - 2015, Vol. 3, No. 3, 1-20

http://dx.doi.org/10.14323/ijuseng.2015.9

\title{
An Aerial Deployed Unmanned Autonomous Glider for Cross-Channel Flight
}

\author{
Mark Jabbal \\ Brunel University London, United Kingdom
}

\begin{abstract}
Jabbal M. (2015). An Aerial Deployed Unmanned Autonomous Glider for Cross-Channel Flight. International Journal of Unmanned Systems Engineering. 3(3): 1-20. This paper describes the technical and operational challenges of the first cross-Channel flight performed by an unmanned autonomous glider. The glider chosen for the attempt was a quarter scale Slingsby Type 45 Swallow. It was found to have a lift-to-drag ratio of 8 , as verified by wind tunnel force balance tests. Essential retrospective aerodynamic refinements to the design, including modifications of the wing root and tip sections and wing aspect ratio, were modelled analytically and found to increase the aircraft's lift-to-drag ratio to 19 . The launch mechanism devised for the modified glider featured a bespoke crate suspended under an airborne helicopter at an altitude of 10,000 ft, from which the aircraft was released from an internal recess. The glider was pre-programmed to fly autonomously via waypoint navigation and completed the 22 mile mission in less than one hour at an average ground speed of 27 knots, a sink rate of $3 \mathrm{ft} / \mathrm{s}$ and with $3,500 \mathrm{ft}$ altitude to spare. The successful flight, which was filmed from onboard cameras and a chase helicopter, represents a unique first in autonomous aviation and is unofficially the longest straight distance flight for an unmanned engineless glider.

(C) Marques Engineering Ltd.
\end{abstract}

\section{Keywords: \\ Aerodynamics \\ Autonomous flight \\ Channel \\ Glider \\ Slingsby T.45 \\ UAV}

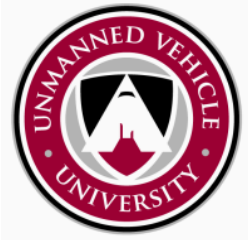

\section{INTRODUCTION}

The attempt to build and fly an unmanned, Corporation (BBC). The series involves scale-model glider across the English presenter, James May, bringing popular Channel was part of a televised technological contraptions up to-date by documentary, 'James May's Toy Stories: using them in real life, large scale Flight Club', produced by Plum Pictures and enterprises. The ambitious and often world commissioned for the British Broadcasting record-breaking projects undertaken involve significant engineering challenges requiring the support of students, technicians and engineers. As an example of one project, a

\section{Correspondence}

Department of Mechanical, Aerospace and Civil Engineering

Brunel University London

Uxbridge, United Kingdom, UB8 3PH

mark_jabbal@hotmail.com
$23 \mathrm{~m}$ long, half tonne, full-size and fully useable footbridge was built with 200,000 parts of "Meccano" mechanical construction kit to span a canal in Liverpool ${ }^{[1]}$. The bridge was a joint venture between the University of Liverpool (Engineering and Architecture) and 
the engineering consultancy, Atkins. The glider project involved collaboration between Brunel University London (Aerospace \& Aviation Engineering) and members of the unmanned aerial vehicle (UAV) and aeromodelling community. The flight course intended for the present project was from Dover, South East England to Calais in northern France via the English Channel's narrowest point, the Strait of Dover - a distance of 22 miles (19.1 nautical miles, Nm). The flight attempt would represent a first for an unmanned, unpowered glider across the English Channel. The original idea was to fly the glider free-flight without any form of on-board control, though this was quickly ruled out because of a mandatory requirement by the Civil Aviation Authority (CAA) for a remote pilot to be able to manually control the glider in the event of an emergency. The glider was to be flown autonomously via waypoint navigation and GPS, thereby classifying it as a UAV according to the CAA.

The closest feat to the present project was the first non-stop Channel-crossing by a radiocontrolled model aeroplane in 1954. The attempt was a joint effort between Colonel Taplin and George Honnest-Redlich, with the former designing the model aircraft and the latter controlling the model from a light aeroplane across the Channel. The aircraft, "Radio Queen" of the now defunct Electric Developments Ltd, was powered by a 3.5cc single cylinder Hunter diesel engine and was hand-launched from Blériot Meadow in Dover. It reached the French coast in $40 \mathrm{~min}$, attaining a maximum altitude of 3,100 ft in flight ${ }^{[2]}$.

The glider chosen for the present attempt was the Slingsby T.45 Swallow, as shown in Fig. 1. The manned version was built by Slingsby Sailplanes Ltd and was first flown in 1957. The glider was of very sturdy build capable of aerobatics and participated in gliding competitions; a small number of T.45's were acquired by the Royal Air Force (RAF) to be used in their Air Training Corps pilot training program. The T.45 is $7.0 \mathrm{~m}$ in length, with a wingspan of $13.2 \mathrm{~m}$ and has an aspect ratio of 12.6 . The glider lift-to-drag ratio, $L / D$, is 26 at $21.6 \mathrm{~m} / \mathrm{s}^{[3]}$.

The T.45 was chosen for several reasons. Firstly, it is an antiquated glider design reminiscent of the Keil-Kraft gliders which James May built during his childhood and thus fitted well with the scope of the programme. Secondly, it has dihedral $\left(3.3^{\circ}\right)$, which would ensure lateral stability in the event of encountering high gusts at altitude. Finally, it has a relatively bulky fuselage, which was needed to accommodate autopilot and GPS for flight tracking, battery supplies for the on-board cameras to film the flight, and servos to operate the rudder and elevator. A 1:4 scale model was deemed the minimum size necessary for the challenge, in order to survive higher altitude buffeting and prevailing Channel conditions.

As the glider was foreseen to be launched at a maximum height of approximately $8,000 \mathrm{ft}$, a glide ratio of $L / D=18$ (including a safety margin of $20 \%$ ) was deemed necessary to complete the $19 \mathrm{Nm}$ mission in accordance with Eq. (1)

$$
\text { Glide ratio }=\frac{\text { mission range }}{\text { launch height }}=\frac{L}{D}
$$

Where $L$ and $D$ are the lift and drag forces of the glider, respectively. This $L / D$ value equates to a glide angle, $\gamma$, of $3.9^{\circ}$ in accordance with Eq. (2)

$$
\text { Glide angle }=\tan ^{-1}\left(\frac{\text { launch height }}{\text { mission range }}\right)=\gamma
$$



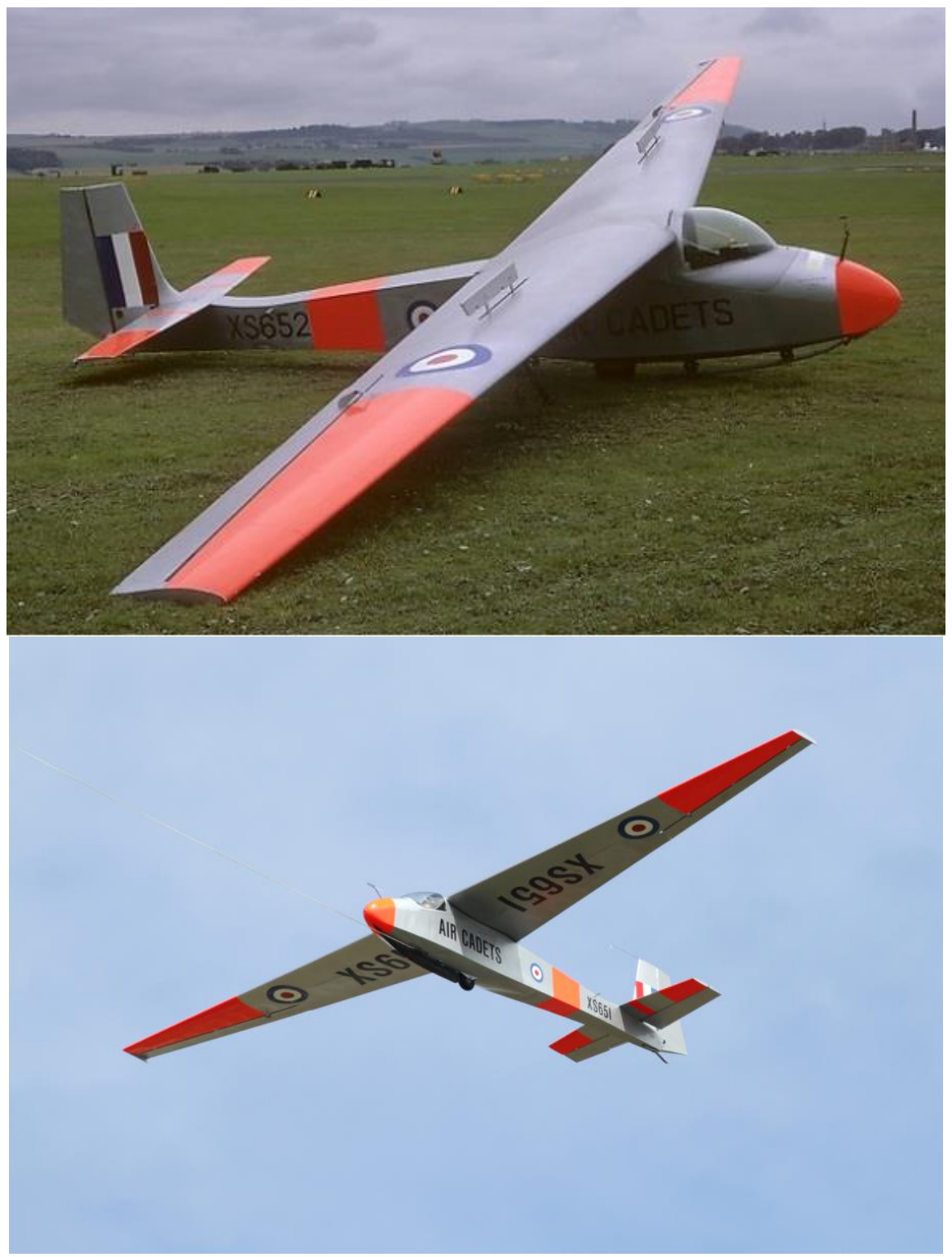

Fig. 1: Slingsby Swallow T.45 manned glider ${ }^{[4,5]}$

II. Original Glider: Performance Verification

A 1:4 scale model of the glider was assembled from laser-cut balsa and plywood parts. To verify the glider's $L / D$ ratio, wind tunnel tests were conducted in the R.J. Mitchell wind tunnel at the University of Southampton. The tunnel is a closed-return facility of $3.6 \mathrm{~m} \times 2.4 \mathrm{~m}$ working section with a maximum speed of $40 \mathrm{~m} / \mathrm{s}$ and a working section freestream turbulence level of less than $0.2 \%{ }^{[6]}$. The glider was mounted to an overhead 6 -component balance to measure lift and drag. Since the model wingspan is $3.3 \mathrm{~m}$ and would therefore span $92 \%$ of the tunnel section, only one wing was attached to the fuselage (Fig. 2) to avoid two-dimensionality of the flow and large discrepancies in induced drag measurement. Such discrepancies become insignificant when the model span is less than 80 per cent of the wind tunnel width ${ }^{[7]}$. 


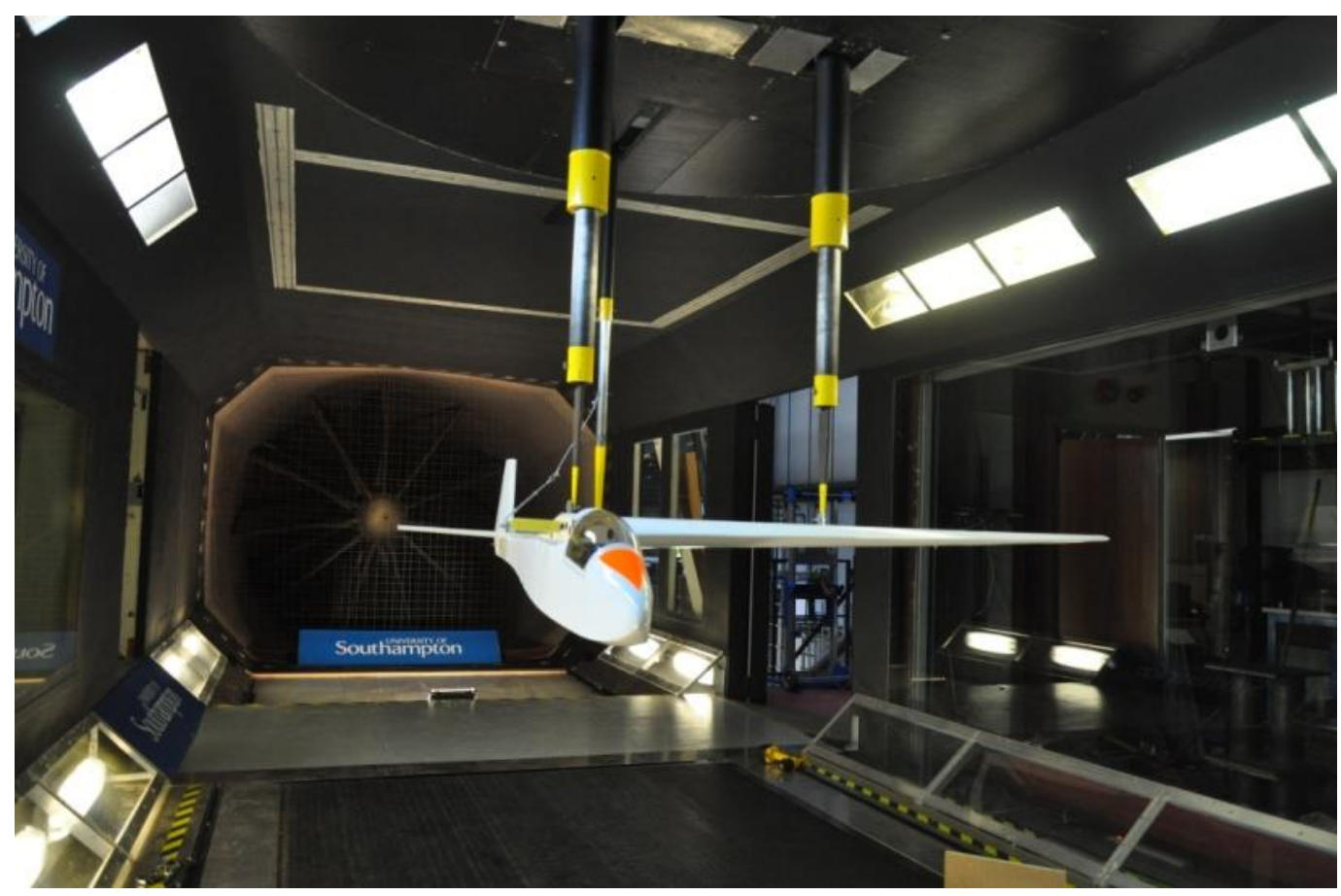

Fig. 2: A model of the 1:4 T.45 glider in the R.J. Mitchell wind tunnel (Photo: University of Southampton)

Lift and drag characteristics of the glider to determine $L / D$ were measured close to the optimum glide speed for minimum drag, $V_{m d}$, which was determined by Eq. (3)

$$
V_{m d}=\left(\frac{1 / \pi A R \cdot e}{C_{D O}}\right)^{0.25}\left(\frac{2(W / S)}{\rho}\right)^{0.5}
$$

Where $A R$ is the wing aspect ratio $(A R=12.6)$; $e$ is the wing efficiency factor $(e=0.9$ based on a wing taper ratio of 0.37 ); $C_{D o}$ is the zero-lift drag coefficient ( $C_{D O} \cong 0.02$ based on the NACA $63_{3} 618$ aerofoil drag polar at $\mathrm{Re}=200,000$ and Ncrit $=9$ or $0.07 \%$ turbulence ${ }^{[8]}$ ); $W / S$ is the wing loading $\left(W / S=8.3 \mathrm{~kg} / \mathrm{m}^{2}\right.$ based on wing area, $S=0.84 \mathrm{~m}^{2}$, and a CAA maximum permissible mass of $7 \mathrm{~kg}$ for a small unmanned aircraft ${ }^{[9]}$ ) and $\rho$ is the air density (assumed sea-level). As a result, $V_{m d}=12.9 \mathrm{~m} / \mathrm{s}$ (25 knots).

Force data was thus measured at free stream velocities close to $V_{m d}(12,13$ and $14 \mathrm{~m} / \mathrm{s})$ and across a range of angles of attack, $\alpha,-5^{\circ}$ to $5^{\circ}$ in increments of $1^{\circ}$. The maximum blockage caused by the model in the tunnel was 3\%, which is within the maximum $5 \%$ recommended value ${ }^{[7]}$. The wind tunnel data acquired was corrected to account for the absent wing and presented in Fig. 3. Fig. 3a shows that the lift curve slope is consistent amongst all velocities, however, notable differences are observed in the drag curve (Fig. 3b), which shows drag coefficient, $C_{D}$, at $14 \mathrm{~m} / \mathrm{s}$ is significantly higher than the lower velocities across the $\alpha$ range. Fig. $3 c$ shows that the maximum $L / D$ ratio achieved in the range of $\alpha$ was approximately 8 . The tests also revealed that the best glide speed for maximum $L / D$ was $13 \mathrm{~m} / \mathrm{s}$, which agrees well with the calculated value from Eq. (2).

Nevertheless, an $L / D$ of 8 is relatively poor in terms of glider performance and is well below the minimum of 18 required in accordance with Eq. (1). Fig. 4 demonstrates the inherit problem of the glider's $L / D$, showing that even at an optimistic $\alpha$ the minimum launch height required for a $19 \mathrm{Nm}$ range is approximately 20,000 ft and hence well above that permissible by the CAA. Consequently, continued use of the T.45 would require retrospective aerodynamic refinement if it was to achieve the required mission range. 
(a)

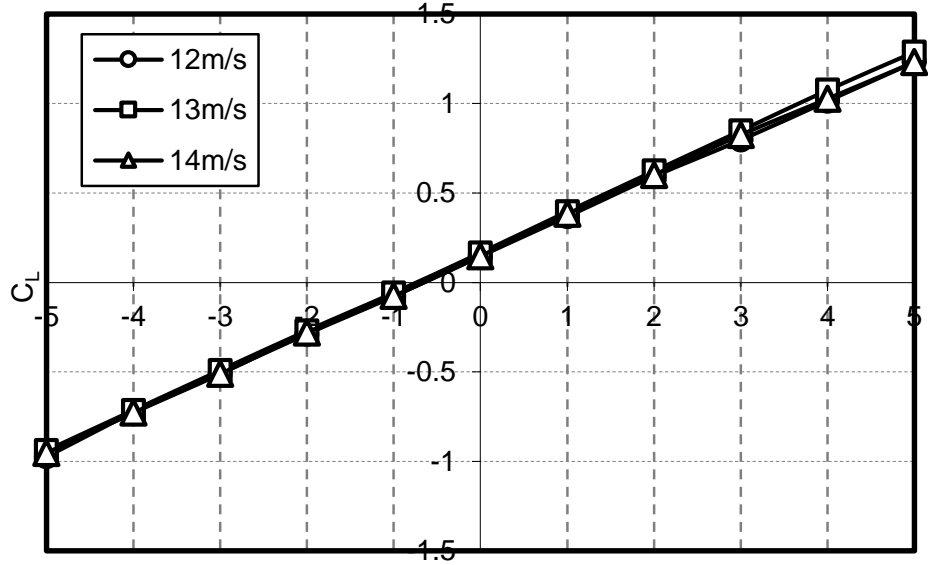

$\alpha\left(^{\circ}\right)$

(b)

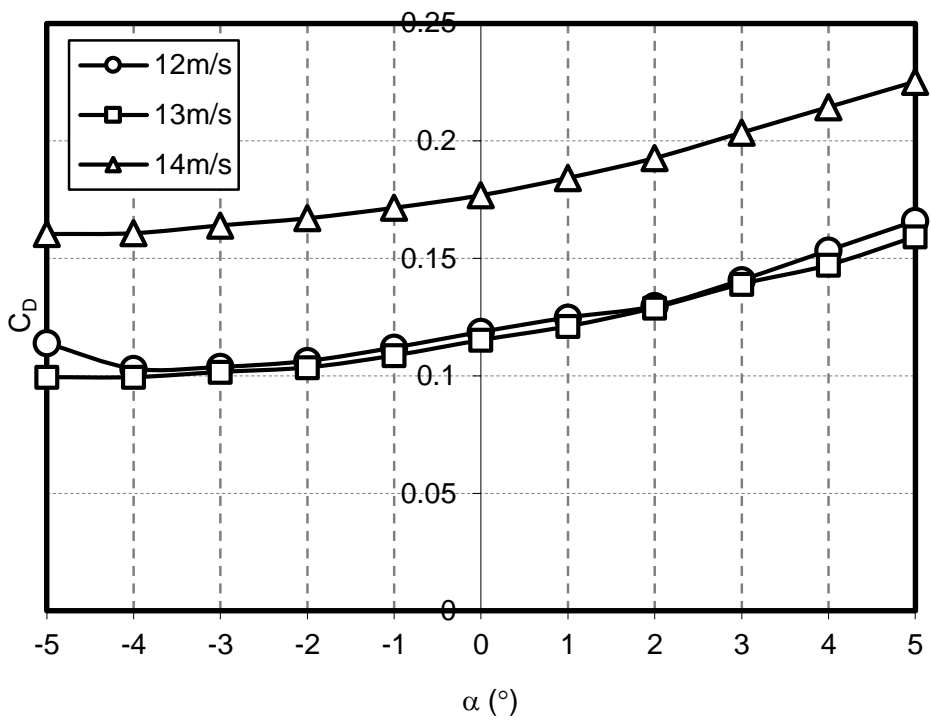

(c)

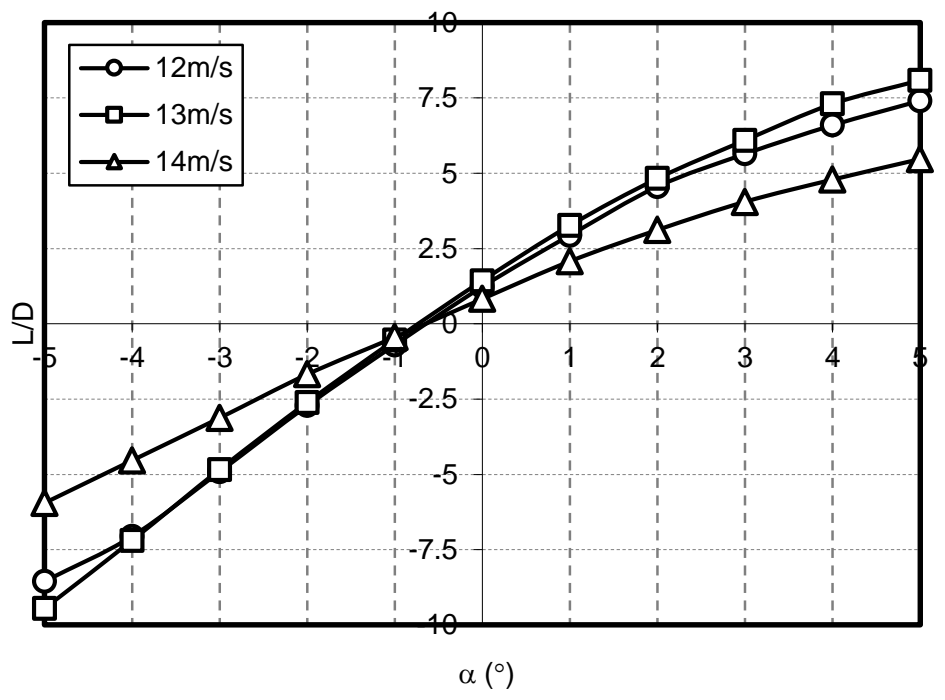

Fig. 3: Wind tunnel test results of original glider: (a) lift curve slope; (b) drag curve slope; and (c) lift-to-drag ratio as a function of angle of attack 


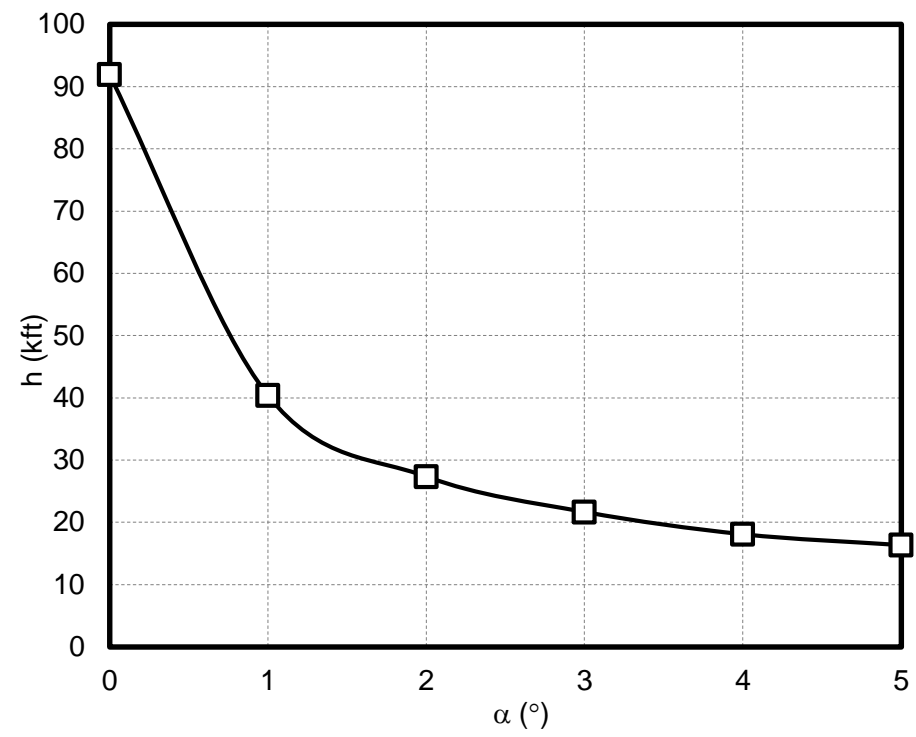

Fig. 4: Estimated launch height for original glider for a required mission range of $19 \mathrm{Nm}$

\section{MODIFIEd GLIDER: DESIGN VALIDATION}

For programme filming purposes, design modifications that were permitted to the wing were restricted to those that would have minimal aesthetic impact on the model. Focus was therefore drawn to modifying the less visible aerofoil section (for zero-lift drag reduction) and wing aspect ratio (for lift-dependent drag reduction) to improve overall $L / D$.

\subsection{Wing Section}

The wing features a NACA 6-series aerofoil (NACA $63_{3} 618$ ) at its root, which transitions to a 4-series aerofoil (NACA 4412) at approximately 80 per cent span. The NACA 6-digit wing sections were designed to give lower drag by maintaining a laminar boundary layer over a significant portion of the wing surface and at least up to the minimum pressure point (suction peak), which is indicated by the second digit in tenths of chord. The last two digits indicate maximum thickness and the fourth digit maximum camber - both as a percentage of the chord. The third (subscript) digit refers to the width of the low-drag range, or 'drag bucket', of these profiles in tenths of lift coefficient above and below the design lift coefficient.

The NACA $63_{3} 618$ wing section thus has a minimum pressure located at $0.3 \mathrm{c}$; a low-drag range of 0.3 , i.e. low-drag maintained at lift coefficients 0.15 above and below the design lift coefficient; and maxima in camber and thickness of $6 \%$ and $18 \%$ chord respectively. An important advantage of the 6-series sections was that, even though they were thick, their very wide drag bucket allowed a glider to perform well at low speeds for soaring and at high speeds for penetrating sinking air between thermals. The NACA 6-series proved a popular choice for many gliders developed at the same time as the T.45 in the late 1950s. Other gliders which had predominantly laminar flow wings utilising the NACA $633_{3} 618$ section include: T.37 (Skylark 1), T.42 (Eagle), Ka 6E, SB 5B, M-100S, Sagitta, Foka 4 and SGS 232 [3,10]

Preliminary research was undertaken to establish whether any modifications could be made to the existing $63_{3} 618$ section to improve its performance. Wortmann ${ }^{[11]}$ reported that a slight change in the nose shape of the NACA 63-618 wing can result in significantly improved section characteristics. Namely, elimination of the sharp velocity peak at $C_{L}=$ 1.265 and a greatly reduced velocity peak at $C_{L}=1.594$, both of which would allow retention of laminar flow to higher lift coefficients and thus a wider drag bucket. The required modification was sufficiently small such that it could be achieved by a fairing and therefore would be conducive to the requirement for minimum impact on aesthetic design.

However, this design modification and the wider use of NACA 6-series aerofoils in general are only beneficial at large Reynolds numbers, Re. Such low-drag profiles do not work well 
at low Re associated with narrow wing chords at low airspeeds, as is the case for the 1:4 T.45 model $\left(R e=2.2 \times 10^{5}\right.$ based on a mean aerodynamic chord $(\mathrm{MAC})=0.26 \mathrm{~m}$ and $V_{m d}=$ $13 \mathrm{~m} / \mathrm{s}$, compared with the full-scale glider at $\mathrm{Re}=1.4 \times 10^{6}$ based on MAC $=1.03 \mathrm{~m}$ and $V_{m d}=21 \mathrm{~m} / \mathrm{s}$ ). At low Reynolds numbers, the 6-series aerofoils are prone to extensive regions of laminar separation and thus high drag. Empirical data comparing the minimum drag coefficient, $c_{d m i n}$, of a 6 -series section (NACA $65_{3} 418$ ) with a 4-series section (NACA 0012) shows the former has a higher $c_{d \min }$ for $\mathrm{Re} \leq 1.7 \times 10^{6}$, which increases with reducing Re such that at $R e \cong 5.0 \times 10^{5}$ its value is comparable to that of a flat plate with turbulent skin friction coefficient ${ }^{[12]}$.

Conversely the 'turbulent' NACA 0012 aerofoil becomes much more laminar compared with the NACA $65_{3} 418$ aerofoil at reducing Reynolds numbers below $\operatorname{Re} \leq 1.7 \times 10^{6}$, with a $c_{d m i n}$ value that approaches the flat plate laminar skin friction drag line. Ironically, the only method of reducing drag of the NACA $63_{3} 618$ wing section at low Reynolds numbers to justify its continued use in the T.45 model would be to force its flow into premature turbulence (i.e. by the use of surface roughness or a 'trip strip'). However, it is most likely that such an aerofoil would offer less predictability in terms of aerodynamic performance and still produce more drag compared with one of the older, 4-digit sections designed for turbulent flow.

It was therefore decided to replace the original 6-series section with a 4-series section; namely using the original tip section (NACA 4412) as the new root section in the modified design. With the root and tip concurrently of the same section it was necessary to increase the camber of the tip section to reduce localised loading, which could otherwise force the tips to stall prematurely and result in a loss in $L / D$. It was therefore decided to replace the original tip section with a NACA 6412 aerofoil. The higher maximum lift coefficient of the strongly cambered profile would be expected to prevent tip stalling at low speeds without any aerodynamic washout. The same spanwise location of transition between the two different sections as the original glider was retained. Fig. 5 illustrates the geometric differences between the original and modified wing sections.

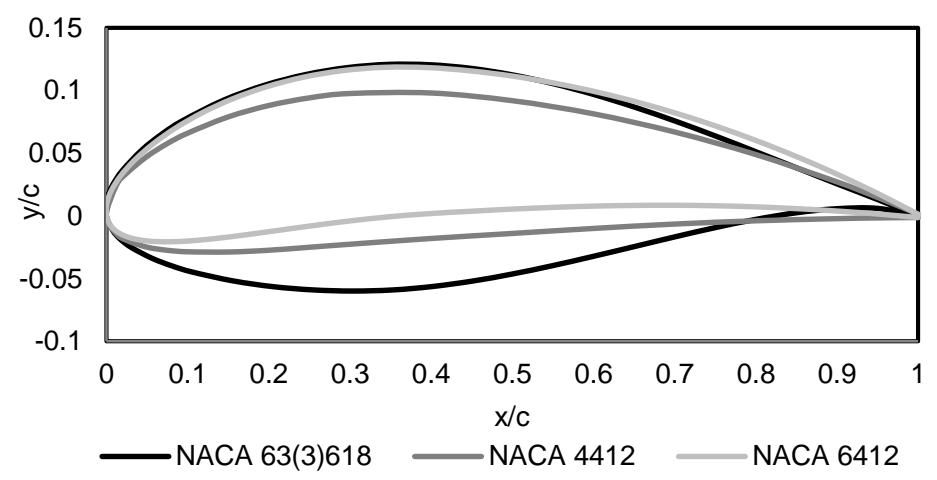

Fig. 5: Comparison of the NACA $63_{3} 618$ (original root), NACA 4412 (original tip; modified root) and NACA 6412 (modified tip) wing sections

\subsection{Wing Aspect Ratio}

At low airspeeds, wingtip vortex/induced drag is normally more than half the total drag of an entire aircraft and so any potential saving here can make a very large improvement in $L / D$ and hence gliding performance. Increasing the aspect ratio of the wing is the most important means available of reducing induced drag. Furthermore as a method of reducing induced drag, increasing aspect ratio would have significantly less aesthetic impact on the model design compared to, say, the addition of wingtip devices such as winglets.

It was decided to add $0.3 \mathrm{~m}$ span at each wing tip, equating to an $18 \%$ overall increase in wingspan to $3.9 \mathrm{~m}$. The root chord was kept at its original value of $0.38 \mathrm{~m}$ due to the original fuselage being retained, with the wing extended along its leading and trailing edge lines to form a new $0.1 \mathrm{~m}$ tip chord (reduced from $0.14 \mathrm{~m}$ ). The resultant wing would have an aspect ratio, $A R$ of 16.2 (increased from 12.6), an area of $0.94 \mathrm{~m}^{2}$ (increased from $0.84 \mathrm{~m}^{2}$ ) and a 
taper ratio of 0.26 (reduced from 0.37). The increase in span increased $A R$, which was estimated to raise the glide ratio by about $15 \%$ due to a reduction in induced drag.

\subsection{Performance Verification}

Due to the time constraints of the project, the identified modifications to improve glider aerodynamic performance could not be verified experimentally in the wind tunnel (there were only a few days available to establish a new wing design and have all the modified wing parts laser cut by an external supplier to be delivered on time for the pre-scheduled build slot). Subsequently, all verification was conducted computationally using XFLR5. XFLR5 uses a range of lifting line theory (LLT), vortex lattice methods (VLM) and panel methods to analyse individual aerofoil or whole aircraft aerodynamics at low Re.

The use of XFLR5 has previously been justified experimentally. A validation experiment ${ }^{[13]}$ with a scale-model Jibe2 sailplane (full-scale length $7.7 \mathrm{~m}$; wingspan: $13.7 \mathrm{~m} ; A R=12.4$ ) was conducted in a wind tunnel, with the measured results at a free stream velocity of 20 and $40 \mathrm{~m} / \mathrm{s}$ compared to the XFLR5 predicted results with and without the body. The results showed that both LLT and VLM schemes correctly predicted the value of the zero-lift angle, with the LLT method best fitting the non-linearity of the lift curve slope, and both gave good predictions of pitching moment coefficient. However, both schemes tend to underestimate total drag with the viscous part of the drag under-predicted. This is also confirmed in a separate validation study ${ }^{[14]}$ for a NACA 4415 aerofoil, in which XFLR5 predicted a $C_{D o}$ value which was $6.25 \%$ lower than the experimental value.

The wing, body and tail configurations were imported into XFLR5 at the desired scale, as illustrated in Fig. 6. A panel method was employed to fully model the glider threedimensionally. Aerodynamics analysis was conducted over the same $\alpha$ range as the wind tunnel tests and at $V_{m d}=13 \mathrm{~m} / \mathrm{s}$. The glider $L / D$ as a function of $\alpha$ is shown in Fig. 7 . Trends in $L / D$ were attained at three different wing loading values, $W / S$. For $W / S=23.5 \mathrm{~kg} / \mathrm{m}^{2}$, which matches the wing loading of the original full-scale glider, Fig. 7 shows that the maximum $L / D$ ratio achieved is approximately 32 at $\alpha=-1^{\circ}$. However, this wing loading equates to a glider mass of $22 \mathrm{~kg}$, which is unfeasibly high. For $W / S=7.45 \mathrm{~kg} / \mathrm{m}^{2}$, which equates to the maximum $7 \mathrm{~kg}$ weight permitted for model aircraft by CAA regulations [9], $L / D=29$ at $\alpha=-1^{\circ}$. In reality the final glider weight was estimated to be $4 \mathrm{~kg}$, accounting for payload and ballast (ball bearings) in the nose to aid longitudinal stability. The resulting wing loading, $W / S=4.25 \mathrm{~kg} / \mathrm{m}^{2}$, gives $L / D=26$ at $\alpha=-1.5^{\circ}$.

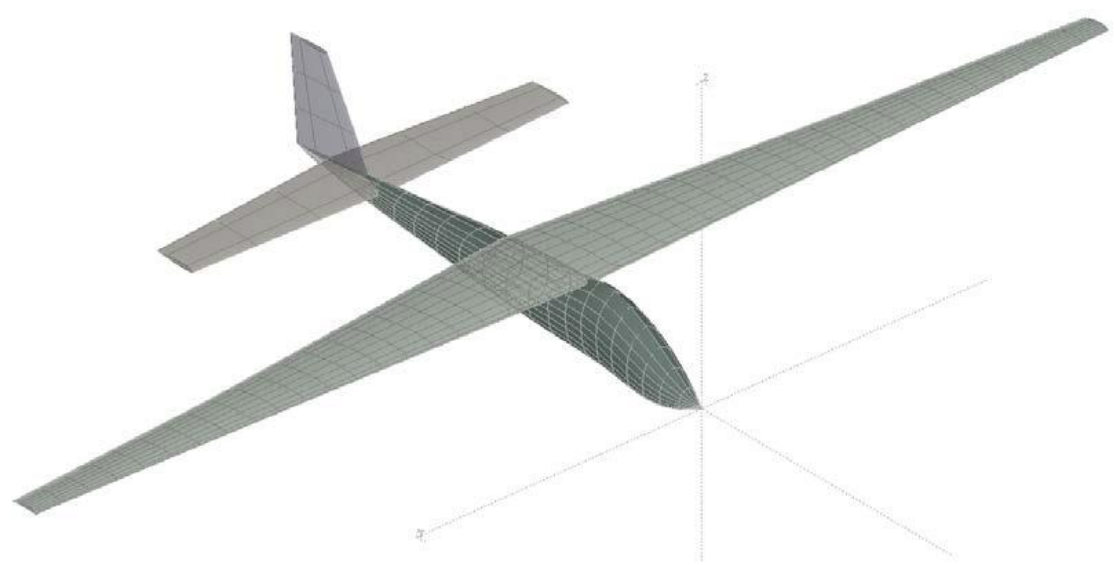

Fig. 6: Isometric view of the modified T.45 glider in XFLR5 with panel distribution 


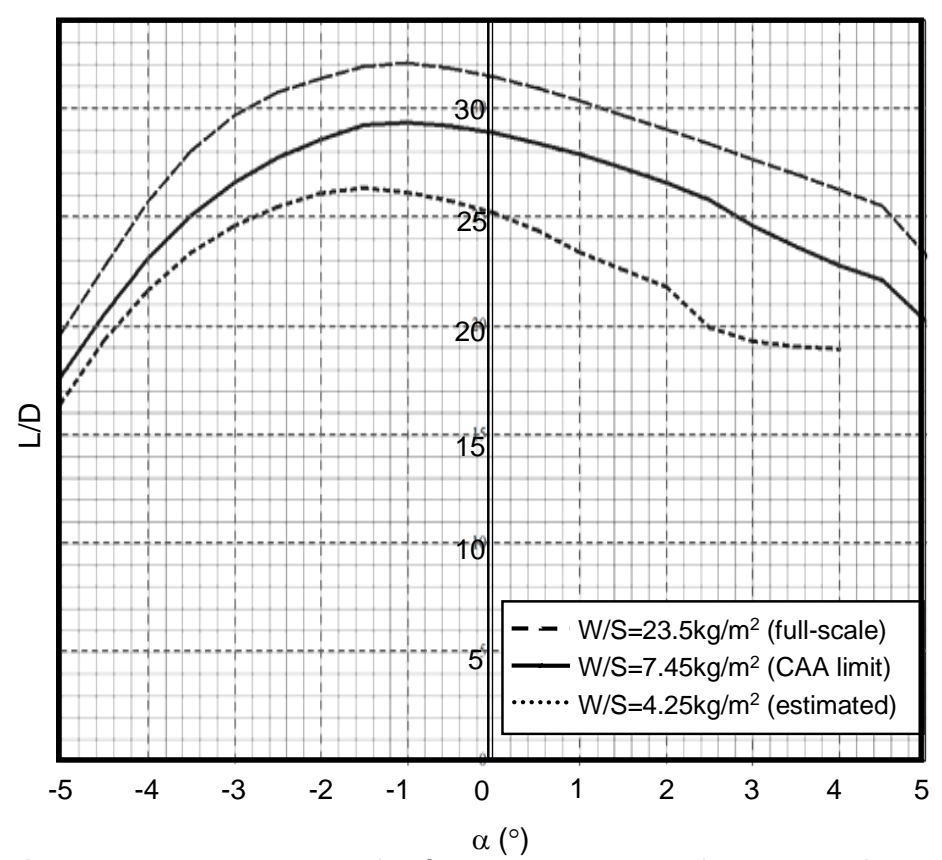

Fig. 7: XFLR5 output of $L / D$ over a range of angles of attack for different maximum wing loading

Taking into account the reported underestimation of $C_{D o}$ in XFLR5 relative to experimental data ${ }^{[14]}$, as well as a $20 \%$ safety factor, the final $L / D$ was estimated to be 19 . This value is still significantly greater than that measured experimentally for the original glider without wing modifications. Most importantly, the modified glider meets the requirement for a minimum glide ratio of 18 to achieve cross-Channel flight. A summary of all modifications from the original glider are detailed in Table 1.

Table 1: Component changes between the original and modified T.45 glider

\begin{tabular}{|c|c|c|c|}
\hline Component & Original & Modification & Justification \\
\hline Root aerofoil & NACA $63_{3} 618$ & NACA 4412 & Reduce laminar separation drag \\
\hline Tip aerofoil & NACA 4412 & NACA 6412 & Reduce high tip loading/stall \\
\hline $\begin{array}{l}\text { Wingspan; } \\
\text { (Aspect ratio) }\end{array}$ & $\begin{array}{l}3.3 \mathrm{~m} \\
(A R=12.6)\end{array}$ & $\begin{array}{l}3.9 \mathrm{~m} \\
(A R=16.2)\end{array}$ & Reduce vortex/induced drag \\
\hline Taper ratio & 0.37 & 0.26 & Inherent result of increasing $A R$ \\
\hline $\begin{array}{l}\text { Airbrakes - } \\
\text { manned glider }\end{array}$ & (removed) & $\mathrm{N} / \mathrm{A}$ & Reduce build complexity/weight \\
\hline $\begin{array}{l}\text { Undercarriage - } \\
\text { manned glider }\end{array}$ & $\begin{array}{l}\text { Wheel \& skid } \\
\text { (removed) }\end{array}$ & $\mathrm{N} / \mathrm{A}$ & Reduce build complexity/weight \\
\hline
\end{tabular}

With the design finalised, a 1:4 scale model of the glider, barring the modified wing sections and out-of-scale wings, was laser cut from balsa and plywood parts for assembly. Joining the modified wing root and cockpit canopy with the original fuselage required some improvising at the wing-fuselage junction through the use of bespoke cut parts. Duct tape was used to act as an aerodynamic seal along the joints. The glider was finally finished with a heat shrink wrap skin. The assembled glider is shown in Fig. 8. 


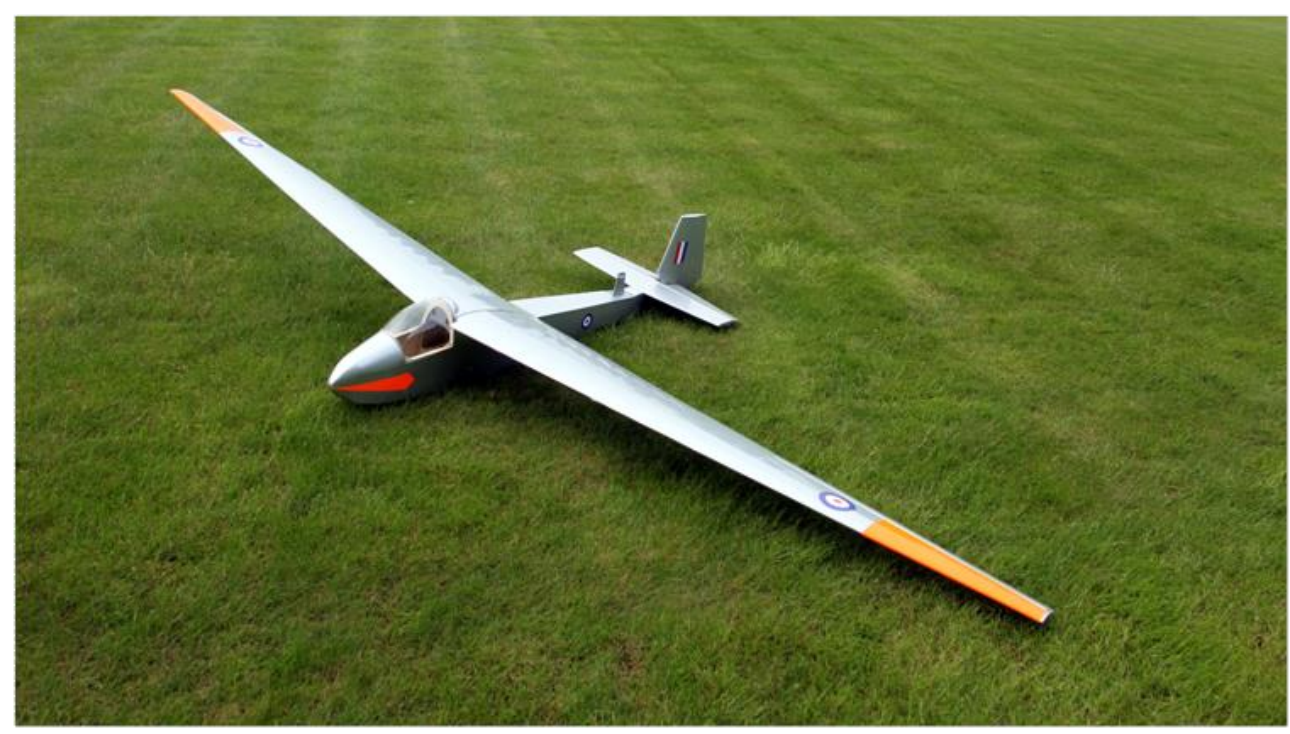

Fig. 8: Final model of the Slingsby Swallow T.45 glider with modified wing

\section{LAUNCh MechanisM}

The most common method of launching a manned glider is either to tow it into the air from the ground using a winch or a moving vehicle, or to tow it behind a powered aircraft. The initial plan for releasing the glider at altitude was from a hot air balloon. A balloon launch however would be highly susceptible to prevailing Channel weather conditions and would offer limited flexibility on the release altitude. In order to provide more flexibility, the glider was to be launched from a helicopter. However the glider could not simply be launched directly out of the helicopter due to the incalculable effect of the helicopter's downwash, let alone the potential risk of it coming into contact with the rotors. Therefore a mechanism was devised to launch the glider from a protective crate suspended beneath the helicopter.

The crate (Fig. 9a) was a wooden structure that loosely fitted around the glider with recess (Fig. 9b) to allow the glider to be deployed. The crate would be suspended approximately 10 $m$ underneath the launch helicopter, a Hughes 369D, via connections at the front and rear of the fuselage and on each wing to keep it level when airborne. The glider was held in the crate by a $24 \mathrm{~V}$ electromagnetic clamp located above the glider cockpit canopy, which could be powered off when the helicopter was airborne thereby releasing the glider. The helicopter pilot had a switch to disengage the electromagnet that was powered by a cable running down the ropes supporting the crate. A windsock was attached to the rear of the crate to ensure it remained stable underneath the helicopter and was facing into the wind during release. A schematic illustrating the launch mechanism is shown in Fig. 9c.

A test of the launch mechanism was carried out to demonstrate its feasibility prior to the flight attempt. Fig. 10 shows a sequence of images captured from a camera attached inside the crate as the glider is released. The successful deployment and the ensuing smooth flight of the glider confirmed the success of the launch mechanism. 
(a)

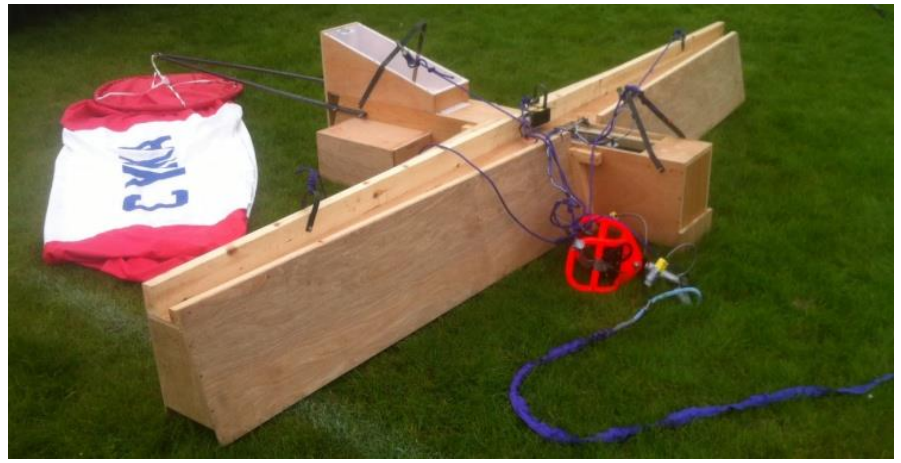

(b)

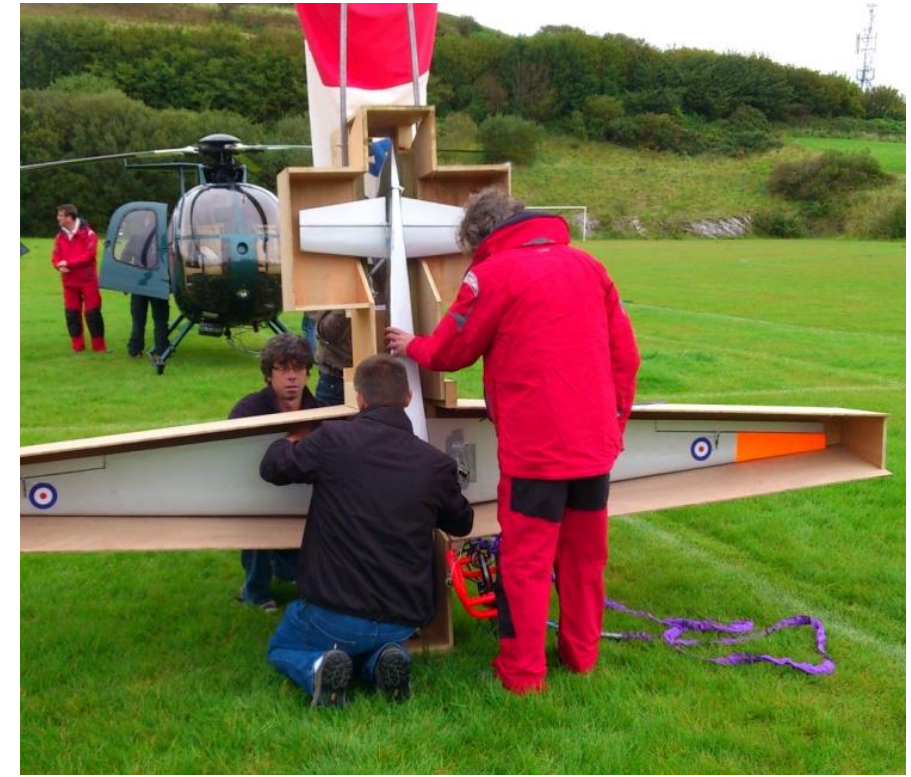

(c)

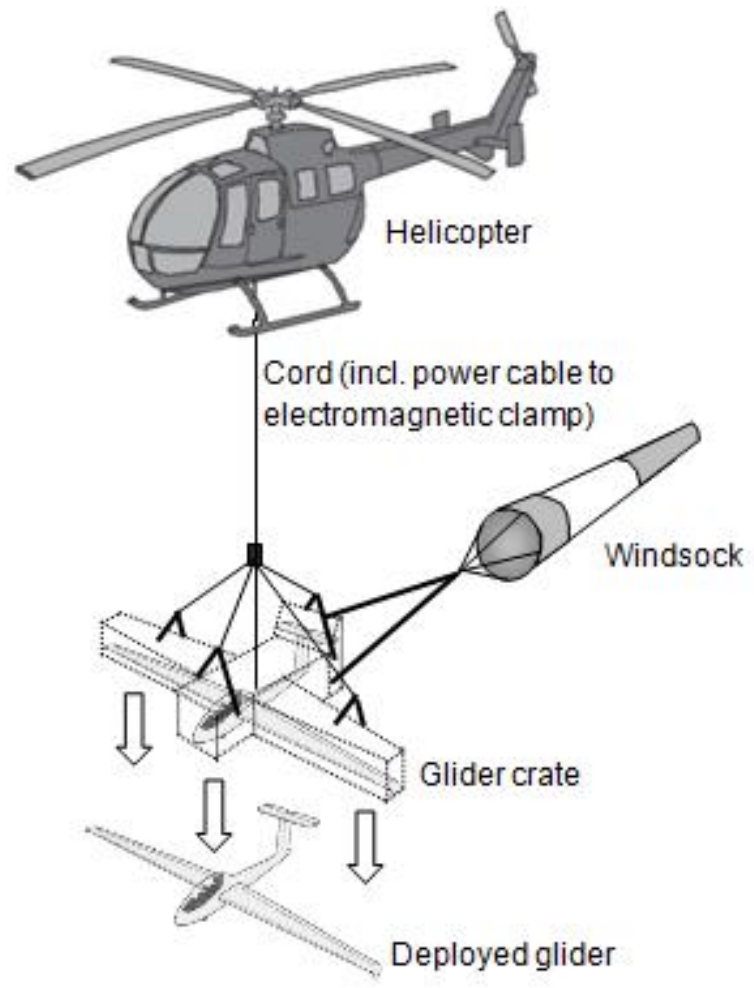

Fig. 9: Glider launch mechanism: (a) isometric view of glider crate; (b) underside view of crate with glider enclosed; and (c) schematic of glider deployment 

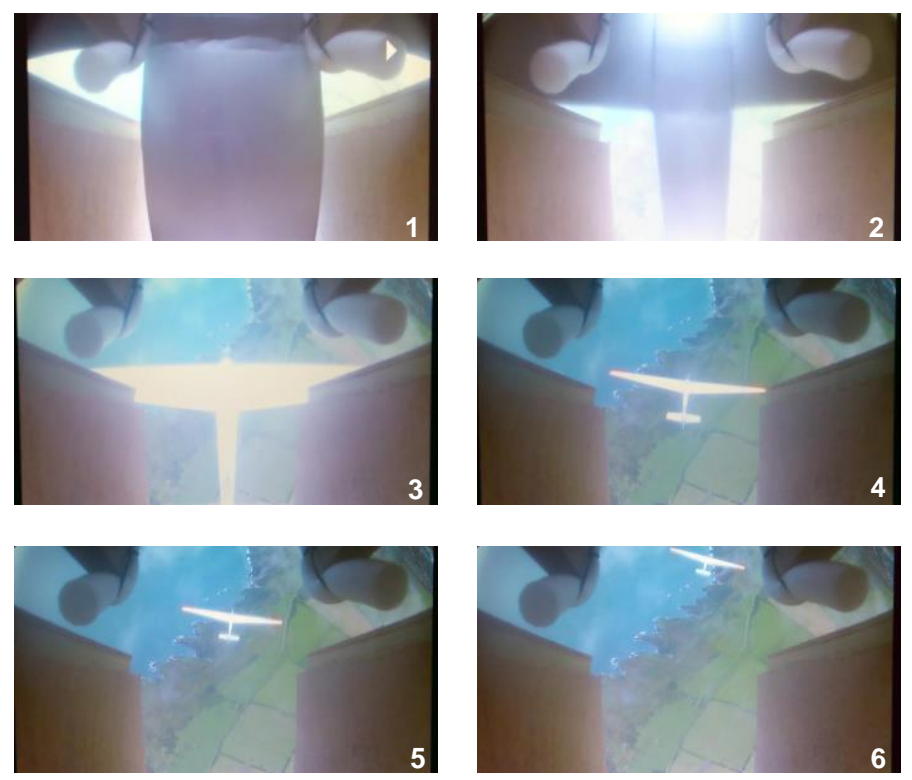

Fig. 10: Launch sequence of the glider from the airborne crate (total duration $=15$ seconds)

\section{GLider Telemetry}

The glider was equipped with an ArduPilot Mega 2560 (Fig. 11), which effectively renders it as a programmable, engineless UAV. The ArduPilot Mega 2560 consists of an autopilot (Fig. 11a) that supports waypoints and mission commands; air speed and pressure sensors (Fig. $11 \mathrm{~b})$ to measure glider speed and altitude, and 3-axis accelerometers and gyroscopes to record any change in the movement of the glider. The ArduPilot interfaces with several servos to move the aileron, elevator and rudder control surfaces. An override by $\mathrm{RC}$ transmitter was also possible for manual control; a mandatory CAA requirement should the remote pilot need to assume control of the glider at any point during its flight.

The glider was also fitted with GPS equipment (Fig. 11a) and a radio tracker for line-ofsight flight monitoring. The radio tracker is a non-commercial device originally developed for high altitude ballooning and consists of a $10 \mathrm{~mW} 434 \mathrm{MHz}$ license exempt transmitter system, which sends the position obtained from the glider GPS. At the receiver end, a high quality narrow band receiver sends the incoming signals to bespoke software on a computer that determines the position relative to a local GPS. The positions are updated on a live updating Google Earth display, which gives a track for the glider flight path. In addition, there is a live display of bearing, altitude and distance from the receiver station to the glider. The signal is very narrow band and low data rate, updating every 15 to 20 seconds.

The autopilot and GPS were mounted inside the cockpit area, accessible via the canopy opening, with the air speed sensor probe mounted in the nose. In addition, three Flycam One High Definition (HD) cameras were fitted to the glider to obtain in-flight film from the glider's perspective. Each ultralight lens was separated out from its camera body and attached to glider-mounted pylons; one under each wing with the starboard lens rear-facing and port lens forward-facing. The third lens was mounted forward-facing at the fuselage-tail junction (visible in Fig. 8). The batteries were positioned in the nose to act as part of the forward ballast, with the camera bodies positioned at the centre of gravity beneath the wings. 
(a)
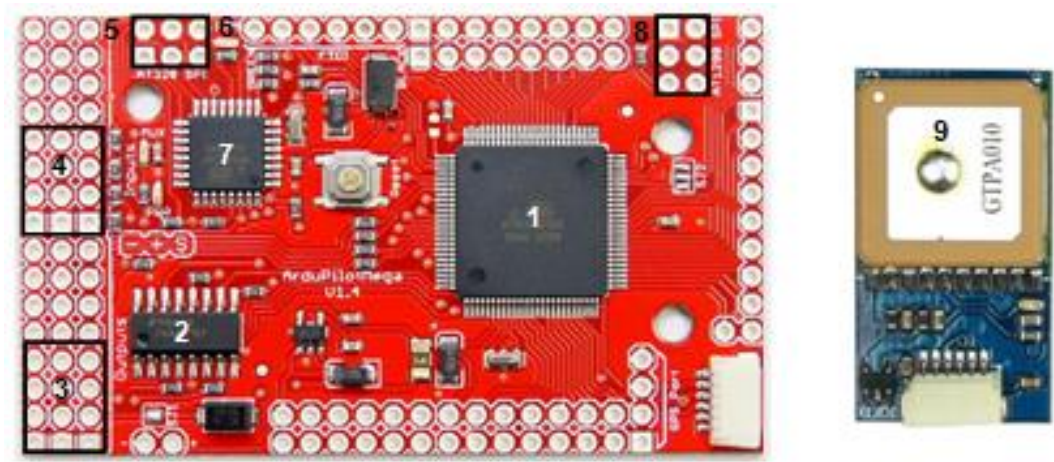

1. Autopilot
2. Multiplexor
3. Outputs
4. Inputs
5. PPM Encoder SPI/ISP Port

6. PPM Encoder Status LED

7. PPM Encoder/Fail Safe

8. ATMega1280 SPI/ISP Port

5. PPM Encoder SPI/ISP Port

9. GPS

(b)
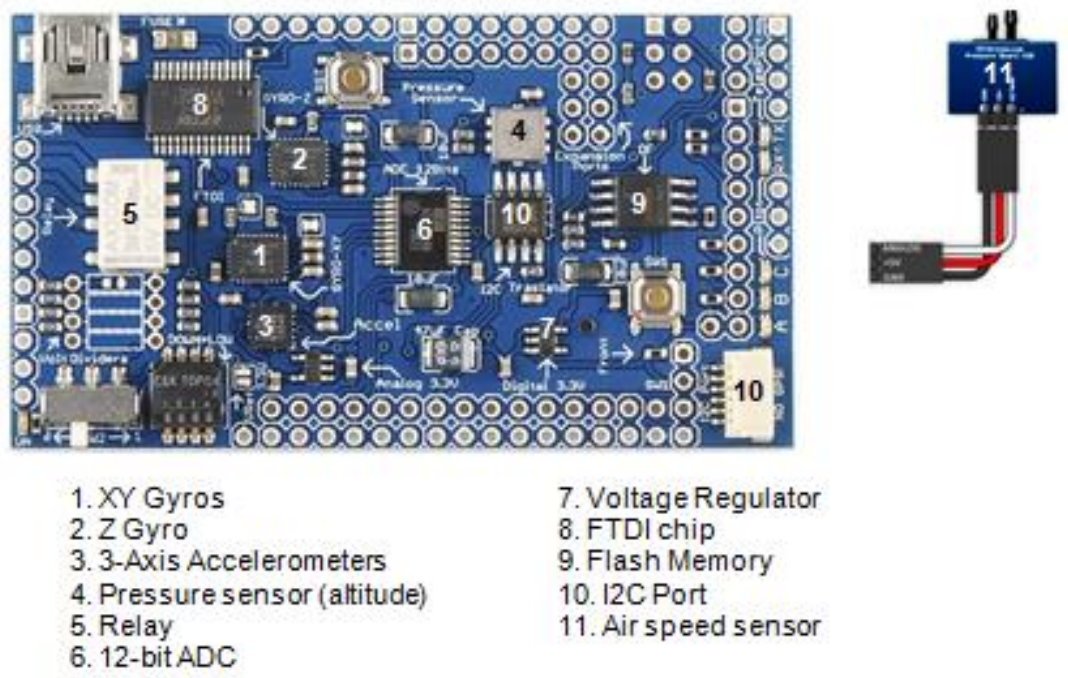

7. Voltage Regulator

8. FTDI chip

9. Flash Memory

10. $12 \mathrm{C}$ Port

11. Air speed sensor

Fig. 11: Telemetry kit: (a) autopilot (ArduPilot Mega 2560) and GPS (Media Tek); (b) sensor board (Oilpan)

\section{Vi. Cross-Channel Flight}

The cross-Channel attempt would be filmed at airborne level from a Robinson R44 helicopter of aerial filming company 'FlyingTV' which would track the glider at distance, and at sea-level from a film crew in a speedboat tracking the glider from a mid-Channel location. A designated remote pilot for the glider was also on board the R44 helicopter in case manual override via $R C$ transmitter was required at any point during the glider's flight.

The original intention was to fly the glider across the English Channel from Dover (51.13, 1.31) to Calais $(50.95,1.85)$, however the French authorities refused to allow the glider to enter their airspace thus ultimately denying the attempt to proceed. The author is not privy to the explicit reasons for permission being denied, though there are several possible explanations. Firstly, there is the unconfirmed stance of the French authorities refusing to recognise the glider as a UAV, even though the CAA had previously done so. Secondly, a French decree concerning operation of Remotely Piloted Aircraft (RPA) in French airspace states that "a remote pilot may not control a RPA if he is on board another moving vehicle" [15]. Although the primary means of flying the glider was by autopilot and GPS, it was also RPA-enabled as a secondary means of control as previously described. This decree therefore could not be complied with given that RPA capability was a mandatory requirement for the glider and that the remote pilot was on board a helicopter. Alternatively, controlling the glider from a fixed ground station at Dover was not feasible as the remote pilot would be 
unable to maintain visual line-of-sight of the glider across the English Channel, thus contravening CAA ${ }^{[9]}$ and French regulations ${ }^{[15]}$.

Although the flight course had to be changed, the intention remained to undertake the 19 $\mathrm{Nm}$ challenge across a channel within the UK. Subsequently, permission was sought and attained from the CAA to replicate the challenge across the Bristol Channel. A new flight path from Ilfracombe $(51.21,-4.12)$ in North Devon to Oxwich Bay $(51.56,-4.15)$ in South Wales was to be attempted, representing the same $19 \mathrm{Nm}$ distance as the English Channel.

The first flight attempt was made on 21 September 2012. However due to the low cloud base on the day (the glider was not permitted to be released above or inside the cloud, but underneath it) and delays of the speedboat crew being in position, thus allowing further deterioration of the weather before launch, the glider was eventually released at an altitude of $2,900 \mathrm{ft}$ - much less than the minimum $8,000 \mathrm{ft}$ deemed necessary. Following its release, the glider initially flew east along the coastline instead of northbound towards Wales. It is likely that this anomaly was due to a script delay in the autopilot engaging to fly to the first waypoint and was therefore, in effect, returning the glider to base (1 mile east of llfracombe) from where the autopilot was switched on and initial GPS coordinates saved. A combination of low release altitude and said autopilot issues resulted in the glider landing in the Bristol Channel only $2.2 \mathrm{Nm}$ from its launch location.

A second and final attempt was scheduled for the following day, 22 September 2012. Clearer skies over the Bristol Channel meant that the glider could be released at its intended altitude; however a prevalent easterly wind made a northbound cross-Channel attempt unfeasible. Consequently the flight course was changed for a second time with the intention to utilise the tailwind and fly the glider westbound from Ilfracombe to Lundy Island $(51.17$, 4.67), which would still replicate the $19 \mathrm{Nm}$ distance of the English Channel between Dover and Calais and the first Bristol Channel attempt. A map summarising all intended and attempted cross-Channel flights is shown in Fig. 12.

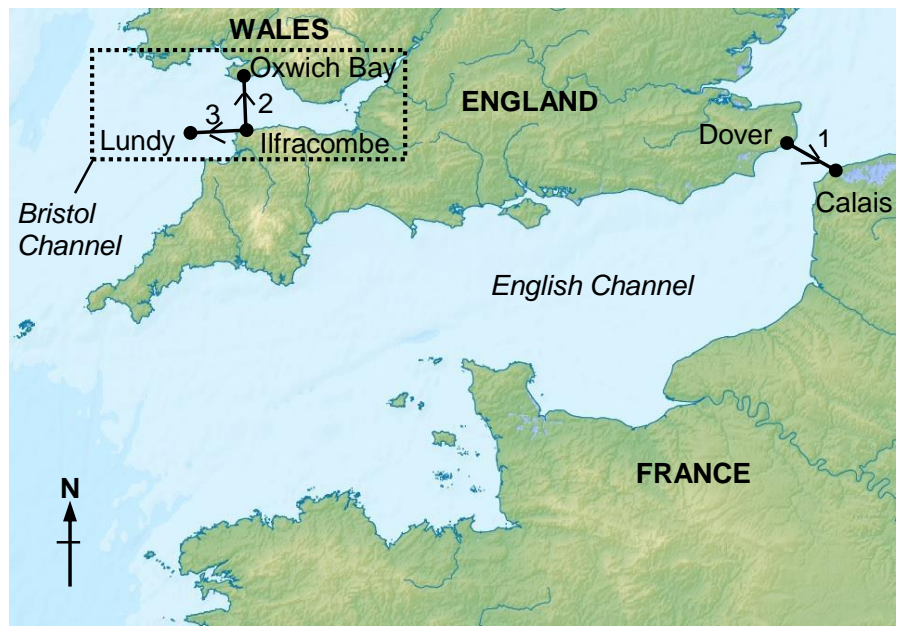

Fig. 12: Designated glider flight path - 1: Dover to Calais (English Channel, aborted);

2: Ilfracombe to Oxwich Bay (Bristol Channel, 1st attempt);

3: Ilfracombe to Lundy Island (Bristol Channel, final attempt)

Fig. 13a shows the glider's flight path in Google maps based on the GPS data log. The glider was released over Woolacombe beach $(51.17,-4.21)$, south west of Ilfracombe (Fig. 13b). The glider was flown manually as it was released from the crate to allow the RC pilot to stabilise it; moving from quiescent to cross flow conditions so quickly may have resulted in the autopilot pulling up the elevator to slow down the glider in response to the airspeed, which could have caused it to hit the crate. Soon thereafter, the autopilot was engaged and, with the GPS, navigated the glider towards Lundy as planned (Fig. 13c). The autopilot was programmed to circle the glider at the target should its remaining height permit it, prior to the $\mathrm{RC}$ pilot taking manual control for only the second and final time during touchdown. The 
straight distance between Woolacombe and Lundy is $17.8 \mathrm{Nm}$, however the total ground distance covered by the glider from release to landing was $22.7 \mathrm{Nm}$ including said circling at Lundy. (Note: actual path length was longer due to 20 second position update of the GPS cutting some turn corners off).

(a)

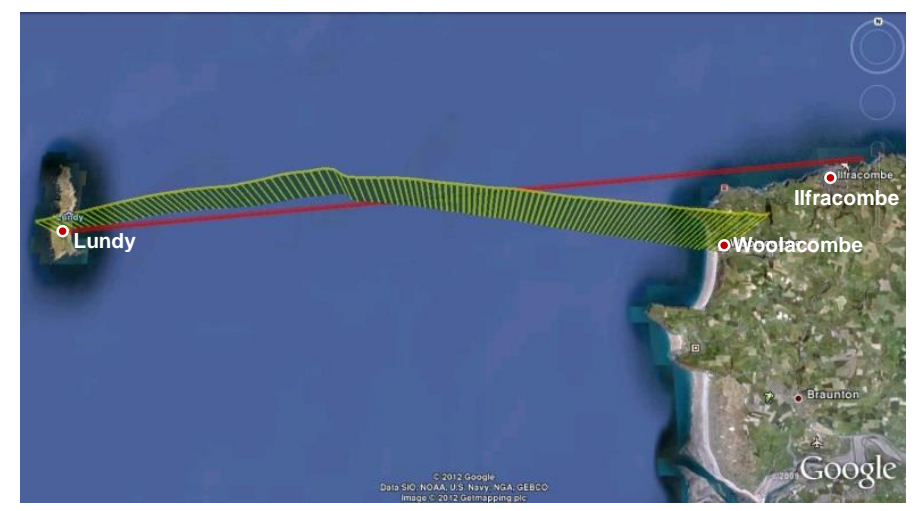

(b)

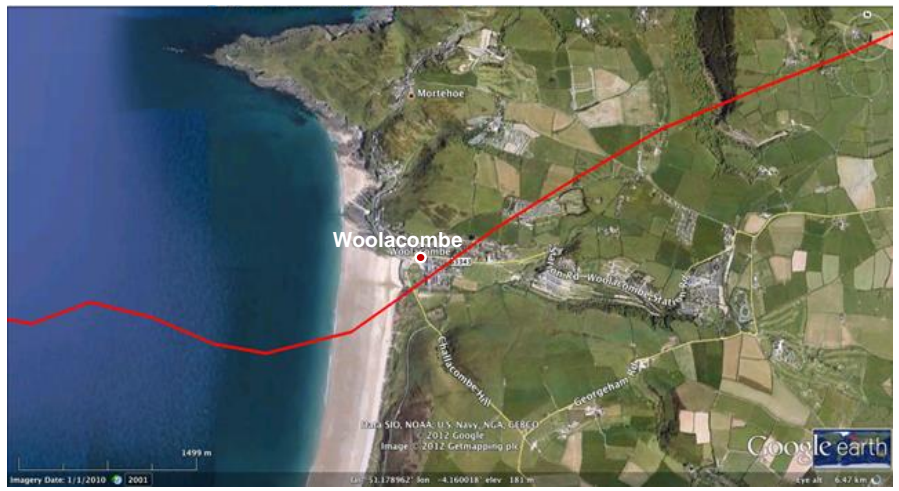

(c)

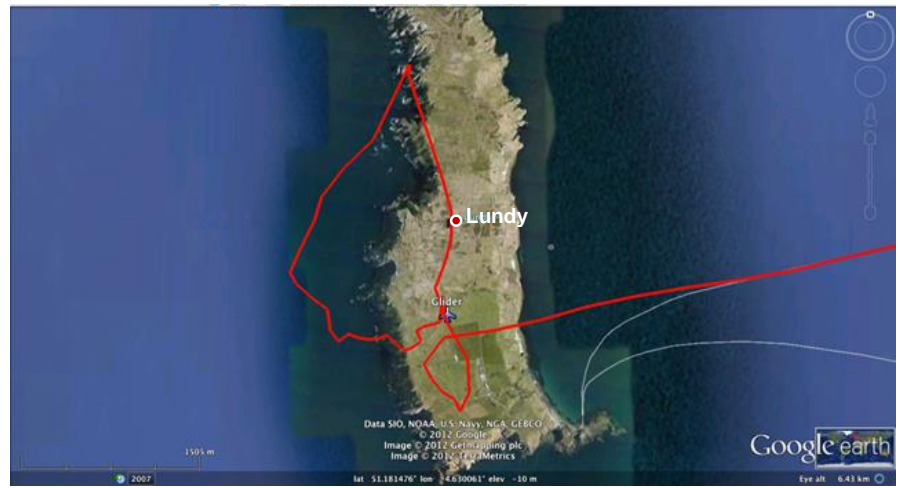

Fig. 13: Glider flight on Google Maps based on GPS: (a) full flight path with height profile; (b) close-up path to release at Woolacombe beach; and (c) close-up path to touchdown at Lundy

Fig. 14 shows the GPS data logs acquired from the glider flight. It should be noted that the GPS data presented covers the flight from release to target (duration of $38.5 \mathrm{~min}$ ) and does not include descent and landing (which takes the total duration to just under $1 \mathrm{~h}$ ). The glider was released at an altitude of approximately 10,000 ft (Fig. 14a), which was higher than the designated $8,000 \mathrm{ft}$ partly for reasons of the favourable weather conditions and also to ensure a greater chance of success for what would be the final attempt. Fig. 14b shows that the glider ground speed rose steadily for the first $22 \mathrm{~min}$ and then experienced a sharp increase with a peak of 37 knots before levelling out again. The glider set an average speed of $26.96 \mathrm{knots}(13.87 \mathrm{~m} / \mathrm{s})$ during flight, which is within $8 \%$ of the value of $V_{m d}$ attained during 
wind tunnel tests $(12.90 \mathrm{~m} / \mathrm{s})$. The glider experienced a moderately steady loss of altitude at an average sink rate of $2.89 \mathrm{ft} / \mathrm{s}$ (Fig. 14c) to the target at Lundy.

(a)

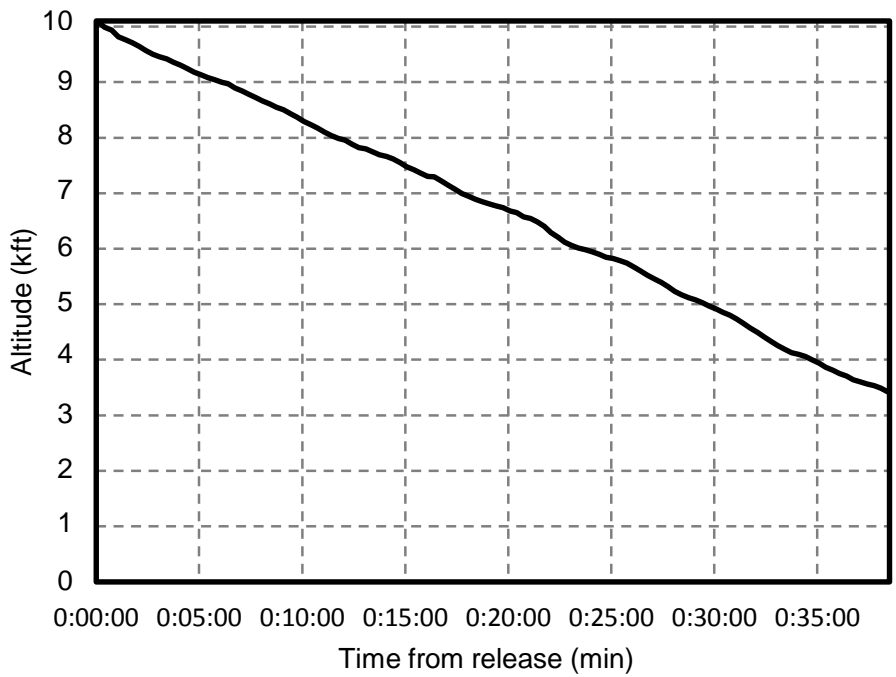

(b)

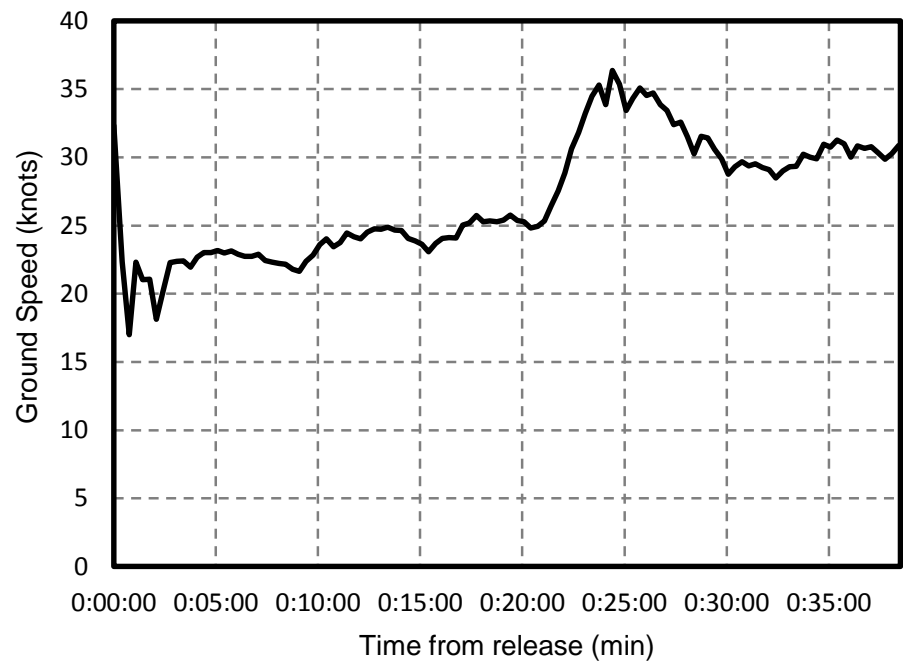

(c)

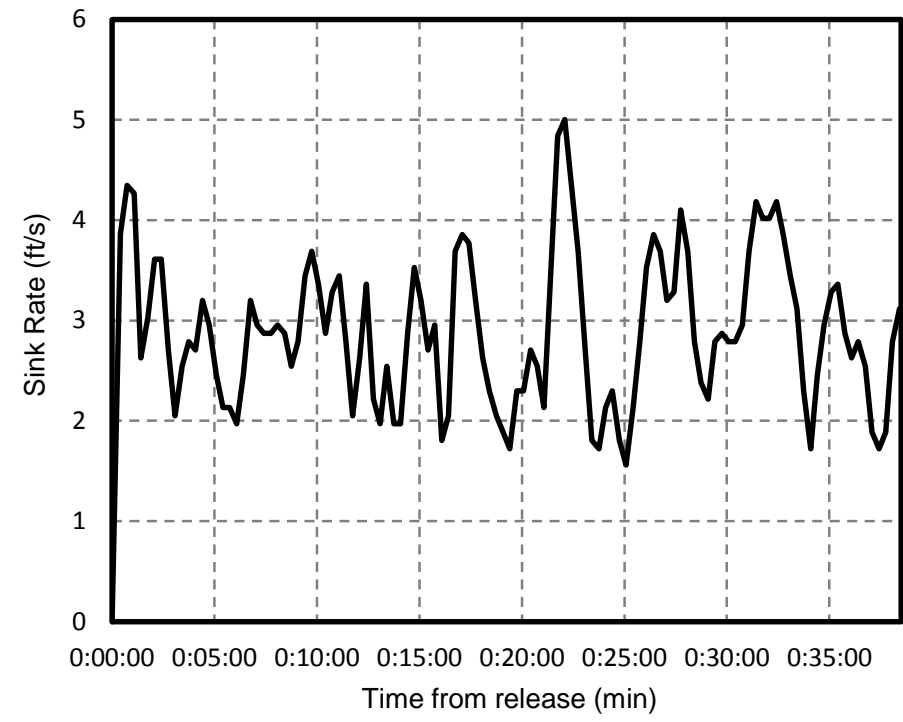

Fig. 14: Glider GPS data logs: (a) altitude; (b) ground speed; and (c) sink rate

The glider reached Lundy with approximately $3,500 \mathrm{ft}$ to spare and thus it's reasonable to 
expect that release from the pre-planned $8,000 \mathrm{ft}$ would similarly have delivered a successful outcome. Depending on how glide ratio is analysed from the in-flight data then $L / D=16.6$ and $\gamma=3.4^{\circ}$ based on a height descent of $6,500 \mathrm{ft}$ from release to target (Fig. 14a) and a horizontal range of $17.8 \mathrm{Nm}$. Alternatively, $L / D=15.8$ and $\gamma=3.6^{\circ}$ based on the ratio of average forward speed, $13.87 \mathrm{~m} / \mathrm{s}$ (Fig. 14b), to average sink speed, $0.88 \mathrm{~m} / \mathrm{s}$ (Fig. 14c). In both cases, $L / D$ is within $20 \%$ of the value derived from XFLR5 analysis of the modified glider. Finally, Fig. 15 shows images of the glider during its flight attained from both the aerial filming helicopter and the on board cameras.

(a)

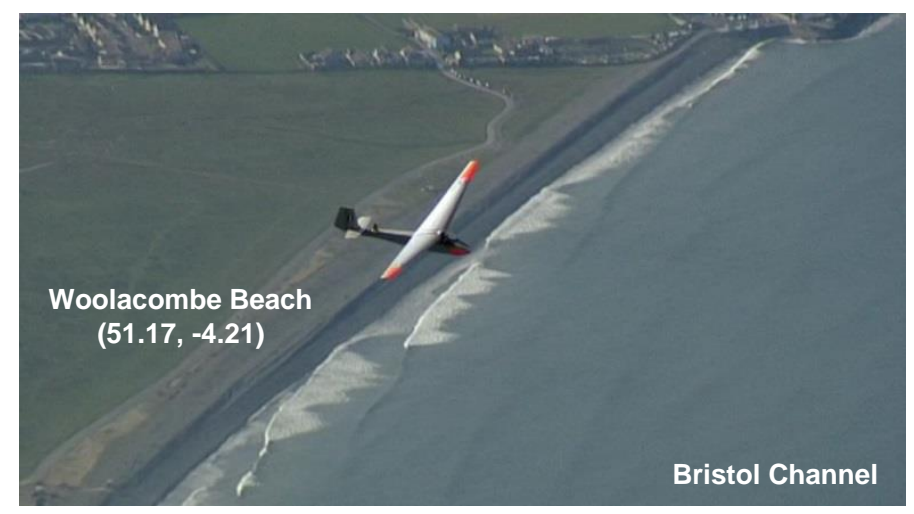

(b)

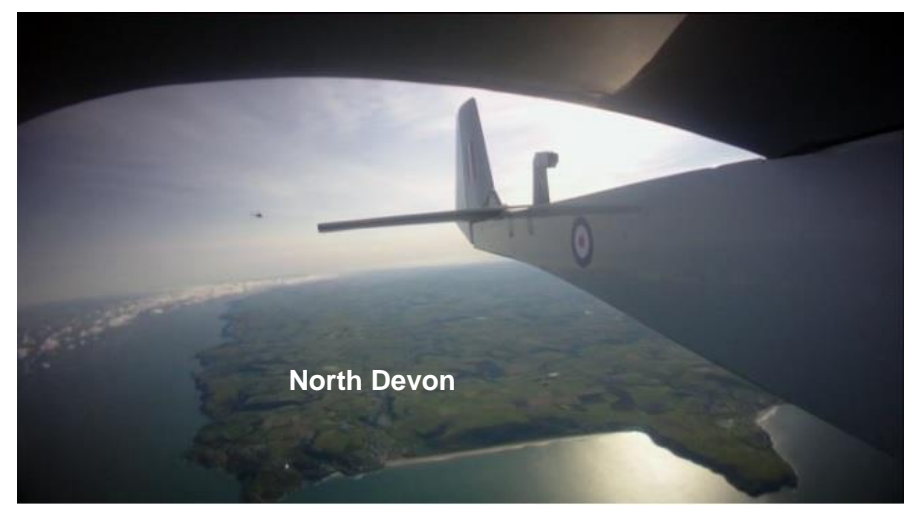

(c)

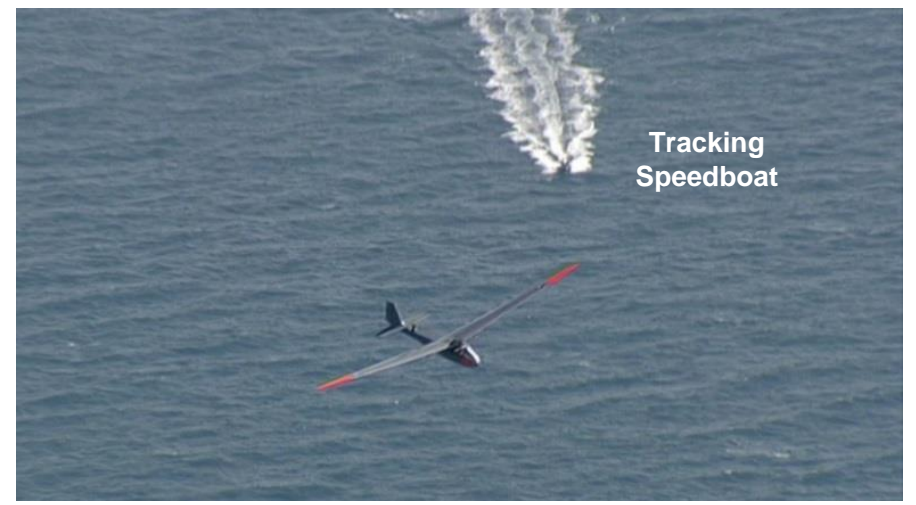


(d)

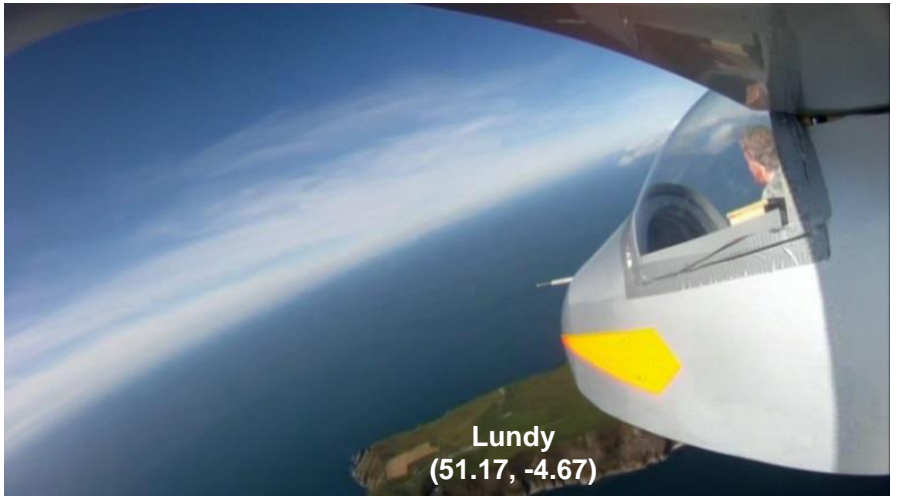

(e)

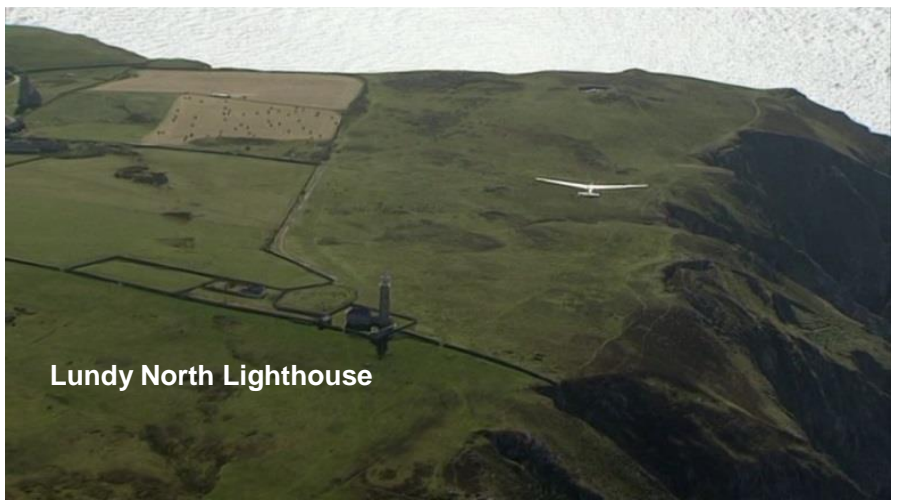

Fig. 15: In-flight images: (a) release over Woolacombe beach; (b) view of North Devon coast from starboard wing camera (note aerial filming helicopter in the distance); (c) glider mid-flight above tracking speedboat; (d) view of Lundy from port wing camera; and (e) descent over Lundy ${ }^{[16]}$

VII. Conclusions

The successful flight between Woolacombe and Lundy makes it, unofficially, the longest straight distance flight performed by an unpowered, gliding UAV of its size. Officially however no records were broken by the flight, as a consequence of it being outside of the strict rules set by the world governing body for aeronautics and astronautics world records, the Fédération Aéronautique Internationale (FAl). For example, within FAI Class F: Model Aircraft category, the glider flight could not be classed as free flight (Class F1) given its primary and secondary means of control were via waypoint navigation/GPS and RC respectively. Nor could the glider be classed as a scale model (Class F4) in "competition" terms given the change in wing sections and out-of-scale extended wingspan. Investigation with the British Model Flying Association (BMFA) and the British Association of Radio Controlled Soaring (BARCS) also revealed no specific class that the flight would full under.

The classification of records achieved by UAVs and autonomous flights has, until quite recently, been a source of some uncertainty within the FAI. An example in case is the TAM5 , which became the first model aircraft to cross the Atlantic Ocean in 2003. The pistonpowered aircraft which flew 1900 miles from Newfoundland, Canada to Mannin Beach, Ireland was controlled by autopilot for more than $99 \%$ of the flight ${ }^{[17]}$. The transatlantic flight was initially recognised with Class F3 (Radio Control Flight) records; F3-142 for straight line distance and F3-141 for duration. These however were later reclassified and replaced with Class F8 (Autonomous Flight) records; F8-908 and F8-907 respectively [18], largely to preserve the integrity of aeromodelling and the associated manual skill with flying RC model aircraft. Application to the relatively new F8 class for the glider flight remains a possibility, pending further investigation.

In total, the project ran for six months from initial brief (March 2012) to successful flight 
(September 2012). Fig. 16 shows the timeline of the project in the overall context of the technical work described in this paper and subsequent terrestrial airing of the flight. Although the project could not be carried out over the English Channel, as originally intended, the challenge was successfully replicated across the same distance in the Bristol Channel. Furthermore, to put the aerodynamic refinements of the original glider into context, the glider would have fallen short of its $19 \mathrm{Nm}$ mission by at least $5 \mathrm{Nm}$ from the same release altitude without the improved wing design.

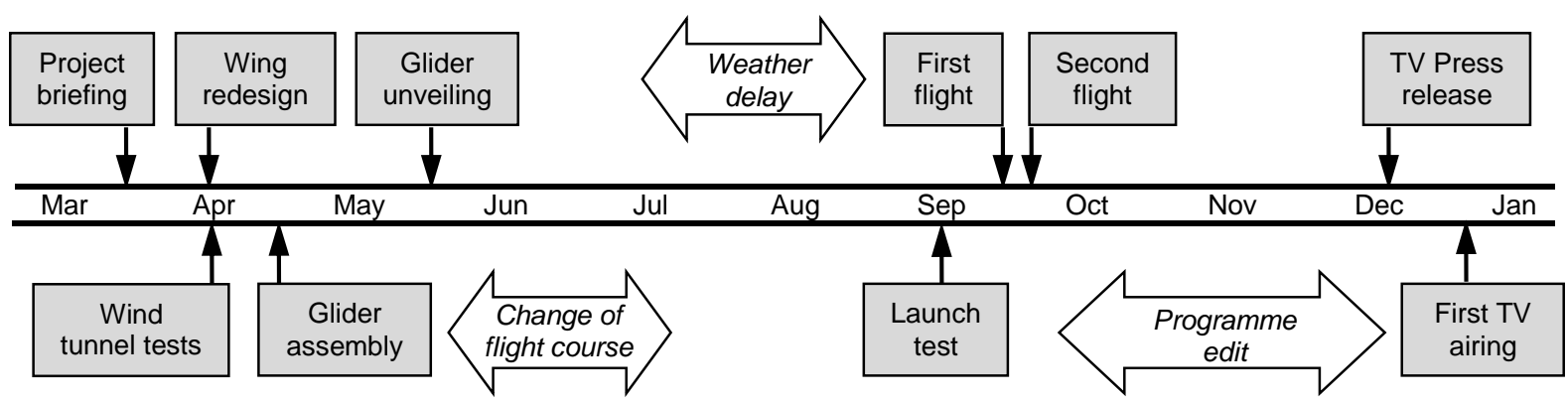

Fig. 16: Timeline for the development, flight and terrestrial airing of the unmanned T.45 glider

\section{Acknowledgments}

The author would like to thank Dr David Marshall (University of Southampton) for the wind tunnel data; Mr Roland Albers (Brunel University London) for the XFLR5 data; and Mr Steve Randall (Random Engineering) for the glider tracker data.

This paper is dedicated to the memory of Mike Smith, Founder of FlyingTV (1955-2014).

\section{REFERENCES}

1. Harrison I. (2009). James May's Toy Stories. Conway. crossref

2. Duncan A. (1954). Channel Crossing Technicalities. Aeromodeller, 644. crossref (http://modelenginenews.org/cardfile/ed_story.html\#t5). Accessed 17 March 2014

3. Simons M. (1996). Slingsby Sailplanes. A Comprehensive History of all Designs. Airlife Publishing Ltd. crossref

4. ATI Collection. (1968). Slingsby Swallow T. Mk. 1. http://www.airteamimages.com/slingsby-t-45-swallow_XS652_united-kingdom---royal-airforce_73796.html. crossref

5. McDonald R. (2011). Slingsby T.45 Swallow. http://commons.wikimedia.org/wiki/File:Slingsby_T.45_Swallow.jpg. crossref

6. R.J. Mitchell Tunnel Facility. (2014). Wind Tunnel Specifications. http://www.southampton.ac.uk/windtunnels/facilities/rjmitchell.page. crossref

7. Barlow JB, Rae WH and Pope A. (1999). Low Speed Wind Tunnel Testing. John Wiley and Sons. crossref

8. Aerofoil Tools. (2014). NACA 63(3)-618 Aerofoil. http://airfoiltools.com/airfoil/details?airfoil=naca633618-il\#polars. crossref

9. Safety Regulation Group. (2013). CAP 658. Model Aircraft: A Guide to Safe Flying. Fourth Edition, Civil Aviation Authority. crossref

10. Thomas F. (1999). Fundamentals of Sailplane Design. College Park Press. crossref

11. Wortmann FX. (1962). Concerning an Improvement of the NACA 63-618 Airfoil. The Journal of the Soaring Society of America, 26: 10. crossref

12. Abbot IH and Von Doenhoff AE. (1959). Theory of Wing Sections: Including a Summary of Airfoil Data. Dover Publications. crossref

13. Deperrois A. (2009). About XFLR5 Calculations and Experimental Measurements. http://www.xflr5.com/docs/Results_vs_Prediction.pdf. crossref

14. MH Aero Tools. (2008). Validation and Accuracy. 
http://www.mh-aerotools.de/airfoils//jf_validation.htm. crossref

15. Gandil P. (2012). Decree Concerning the Design of Civil Aircraft which Fly Without Anyone on Board, Their Conditions of Use, and the Skills Required for Their Users. DEVA1206042A. Official Journal of the French Republic, Ministry of Ecology, Sustainable Development, Transport and Housing. crossref

16. Plum Pictures. (2013). James May's Toy Stories: Balsa Wood Glider, DVD (Region 2), Dazzler Media Limited. crossref

17. Bell R. (2004). Record-setting Transatlantic Flight. Model Airplane News, 84-88. crossref 18. FAl World Records. (2014). New Category for Aeromodelling F8 - Autonomous Flight. http://www.fai.org/news/31938-fai-news-15-06. crossref

$\begin{array}{ll}\text { AR } & \text { aspect ratio } \\ \text { BARCS } & \text { British Association of Radio Controlled Soaring } \\ \text { BBC } & \text { British Broadcasting Corporation } \\ \text { BMFA } & \text { British Model Flying Association } \\ C & \text { chord length (m) } \\ \text { CAA } & \text { Civil Aviation Authority } \\ C_{D} & \text { drag coefficient } \\ C_{D O} & \text { zero-lift drag coefficient } \\ C_{L} & \text { lift coefficient } \\ e & \text { wing efficiency factor } \\ \text { FAl } & \text { Fédération Aéronautique Internationale } \\ \text { GPS } & \text { Global Positioning System } \\ h & \text { altitude (ft) } \\ \text { L/D } & \text { lift-to-drag ratio } \\ \text { LLT } & \text { Lifting Line Theory } \\ \text { MAC } & \text { mean aerodynamic chord (m) } \\ \text { NACA } & \text { National Administrative Committee for Aeronautics } \\ \text { RAF } & \text { Royal Air Force } \\ \text { RC } & \text { radio control } \\ \text { Re } & \text { Reynolds number } \\ \text { RPA } & \text { remotely piloted aircraft } \\ S & \text { wing area (m²) } \\ \text { UAV } & \text { unmanned aerial vehicle } \\ \text { VLM } & \text { Vortex Lattice Method } \\ V \text { md } & \text { minimum drag speed (m/s) } \\ W / S & \left.\text { wing loading (kg/m }{ }^{2}\right) \\ x, y & \text { Cartesian coordinates } \\ \alpha & \\ \gamma & \text { angle of attack }\left(^{\circ}\right) \\ \rho & \text { glide angle }\left({ }^{\circ}\right) \\ & \left.\text { air density (kg/m }{ }^{3}\right) \\ & \end{array}$

